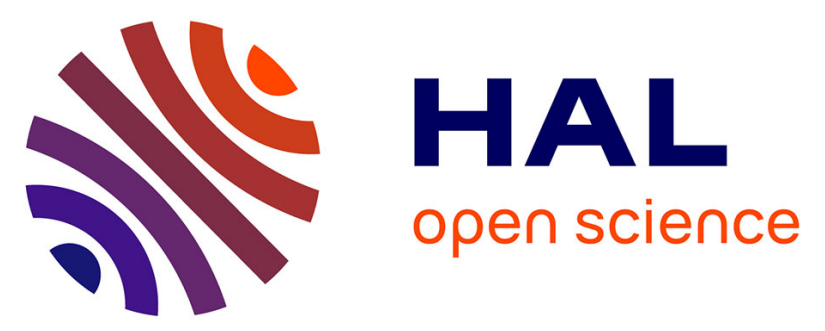

\title{
Optimizing COVID-19 surveillance in long-term care facilities: a modelling study
}

David R.M. Smith, Audrey Duval, Koen Pouwels, Didier Guillemot, Jérôme Fernandes, Bich-Tram Huynh, Laura Temime, Lulla Opatowski

\section{- To cite this version:}

David R.M. Smith, Audrey Duval, Koen Pouwels, Didier Guillemot, Jérôme Fernandes, et al.. Optimizing COVID-19 surveillance in long-term care facilities: a modelling study. BMC Medicine, 2020, 18 (1), pp.386. 10.1186/s12916-020-01866-6 . pasteur-03087175

\section{HAL Id: pasteur-03087175}

\section{https://hal-pasteur.archives-ouvertes.fr/pasteur-03087175}

Submitted on 23 Dec 2020

HAL is a multi-disciplinary open access archive for the deposit and dissemination of scientific research documents, whether they are published or not. The documents may come from teaching and research institutions in France or abroad, or from public or private research centers.
L'archive ouverte pluridisciplinaire $\mathbf{H A L}$, est destinée au dépôt et à la diffusion de documents scientifiques de niveau recherche, publiés ou non, émanant des établissements d'enseignement et de recherche français ou étrangers, des laboratoires publics ou privés.

\section{(c)(1)}

Distributed under a Creative Commons Attribution| 4.0 International License 


\title{
Optimizing COVID-19 surveillance in long- term care facilities: a modelling study
}

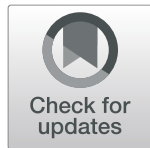

David R. M. Smith ${ }^{1,2,3^{*+}}$ DE, Audrey Duval ${ }^{1,2+}$, Koen B. Pouwels ${ }^{4,5}$, Didier Guillemot ${ }^{1,2,6}$, Jérôme Fernandes ${ }^{7}$, Bich-Tram Huynh ${ }^{1,2}$, Laura Temime ${ }^{3,8 \neq}$, Lulla Opatowski ${ }^{1,2 \neq}$ and on behalf of the AP-HP/Universities/Inserm COVID-19 research collaboration

\begin{abstract}
Background: Long-term care facilities (LTCFs) are vulnerable to outbreaks of coronavirus disease 2019 (COVID-19). Timely epidemiological surveillance is essential for outbreak response, but is complicated by a high proportion of silent (non-symptomatic) infections and limited testing resources.

Methods: We used a stochastic, individual-based model to simulate transmission of severe acute respiratory syndrome coronavirus 2 (SARS-CoV-2) along detailed inter-individual contact networks describing patient-staff interactions in a real LTCF setting. We simulated distribution of nasopharyngeal swabs and reverse transcriptase polymerase chain reaction (RT-PCR) tests using clinical and demographic indications and evaluated the efficacy and resource-efficiency of a range of surveillance strategies, including group testing (sample pooling) and testing cascades, which couple (i) testing for multiple indications (symptoms, admission) with (ii) random daily testing.

Results: In the baseline scenario, randomly introducing a silent SARS-CoV-2 infection into a 170-bed LTCF led to large outbreaks, with a cumulative 86 (95\% uncertainty interval 6-224) infections after 3 weeks of unmitigated transmission. Efficacy of symptom-based screening was limited by lags to symptom onset and silent asymptomatic and pre-symptomatic transmission. Across scenarios, testing upon admission detected just $34-66 \%$ of patients infected upon LTCF entry, and also missed potential introductions from staff. Random daily testing was more effective when targeting patients than staff, but was overall an inefficient use of limited resources. At high testing capacity (> 10 tests/100 beds/day), cascades were most effective, with a 19-36\% probability of detecting outbreaks prior to any nosocomial transmission, and 26-46\% prior to first onset of COVID-19 symptoms. Conversely, at low capacity ( $<2$ tests/100 beds/day), group testing strategies detected outbreaks earliest. Pooling randomly selected patients in a daily group test was most likely to detect outbreaks prior to first symptom onset (16-27\%), while pooling patients and staff expressing any COVID-like symptoms was the most efficient means to improve surveillance given resource limitations, compared to the reference requiring only 6-9 additional tests and 11-28 additional swabs to detect outbreaks 1-6 days earlier, prior to an additional 11-22 infections.

(Continued on next page)
\end{abstract}

\footnotetext{
* Correspondence: david.smith@pasteur.fr

${ }^{\dagger}$ David R. M. Smith and Audrey Duval contributed equally to this work.

‡Laura Temime and Lulla Opatowski contributed equally to this work.

'Institut Pasteur, Epidemiology and Modelling of Antibiotic Evasion (EMAE),

Paris, France

${ }^{2}$ Université Paris-Saclay, UVSQ, Inserm, CESP, Anti-infective evasion and

pharmacoepidemiology team, Montigny-Le-Bretonneux, France

Full list of author information is available at the end of the article
}

(c) The Author(s). 2020 Open Access This article is licensed under a Creative Commons Attribution 4.0 International License, which permits use, sharing, adaptation, distribution and reproduction in any medium or format, as long as you give appropriate credit to the original author(s) and the source, provide a link to the Creative Commons licence, and indicate if changes were made. The images or other third party material in this article are included in the article's Creative Commons licence, unless indicated otherwise in a credit line to the material. If material is not included in the article's Creative Commons licence and your intended use is not permitted by statutory regulation or exceeds the permitted use, you will need to obtain permission directly from the copyright holder. To view a copy of this licence, visit http://creativecommons.org/licenses/by/4.0/. The Creative Commons Public Domain Dedication waiver (http://creativecommons.org/publicdomain/zero/1.0/) applies to the data made available in this article, unless otherwise stated in a credit line to the data. 
(Continued from previous page)

Conclusions: COVID-19 surveillance is challenged by delayed or absent clinical symptoms and imperfect diagnostic sensitivity of standard RT-PCR tests. In our analysis, group testing was the most effective and efficient COVID-19 surveillance strategy for resource-limited LTCFs. Testing cascades were even more effective given ample testing resources. Increasing testing capacity and updating surveillance protocols accordingly could facilitate earlier detection of emerging outbreaks, informing a need for urgent intervention in settings with ongoing nosocomial transmission.

Keywords: SARS-CoV-2, COVID-19, Testing, Infectious disease surveillance, Long-term care, Transmission dynamics, Computational modelling, Mathematical modelling, Contact network, Public health

\section{Background}

From nursing homes to rehabilitation hospitals, longterm care facilities (LTCFs) worldwide are hotspots for outbreaks of coronavirus disease 2019 (COVID-19) [1]. LTCF patients (or residents) require continuing care, live in close proximity to one another, and are typically elderly and multimorbid, placing them at elevated risk of both acquiring severe acute respiratory syndrome coronavirus 2 (SARS-CoV-2, the virus) and suffering severe outcomes from COVID-19 (the disease) [2-4]. Healthcare workers (HCWs) are also susceptible to infection and, amidst imperfect hygiene and infection prevention measures, potentially transmit the virus through necessary daily interactions with both patients and staff $[1,5]$. Although the full extent of the ongoing pandemic is unclear and ever-evolving, LTCFs have and continue to bear a disproportionate burden of SARS-CoV-2 infection and COVID-19 mortality [3, 6, 7]. Across Europe, for instance, LTCFs have accounted for an estimated 30-60\% of all COVID-19 deaths as of June 2020 [8].

Effective COVID-19 surveillance is essential for timely outbreak detection and implementation of necessary public health interventions to limit transmission, including case isolation, contact tracing and enhanced infection prevention [9-11]. The current gold-standard diagnostic test for active SARS-CoV-2 infection is reverse transcriptase polymerase chain reaction (RT-PCR), typically performed on clinical specimens from nasopharyngeal swabs [12]. Though sensitive and highly specific, RT-PCR is relatively resource intensive, must be outsourced for institutions lacking on-site infrastructure, and is widely subject to shortages and specific usage guidelines. For instance, a common practice in LTCFs in France, the Netherlands, the UK, the USA, and elsewhere has been to restrict testing to individuals presenting with characteristic COVID-19 symptoms [4, 13-15]. Yet symptomatic infections represent just the tip of the iceberg: many infections cause no or only mild symptoms, produce high quantities of virus in the absence of symptoms, and experience relatively long delays until symptom onset [16-19]. Silent transmission from asymptomatic and pre-symptomatic infections is a known driver of COVID-19 outbreaks [20, 21], with non-symptomatic cases acting as Trojan Horses, unknowingly introducing the virus into healthcare institutions and triggering nosocomial spread [8, 22, 23].

Insufficient surveillance systems, including those lacking testing capacity or relying only on symptoms as indications for testing, have been identified as aggravating factors for COVID-19 outbreaks in LTCFs [8, 16, 2427]. Various surveillance strategies have been proposed to optimize testing while accounting for the particular transmission dynamics of SARS-CoV-2, including randomly testing HCWs, testing all patients upon admission, and universal or serial testing [28-30]. Yet COVID-19 surveillance is limited in practice by available testing capacity and health-economic resources, particularly for institutions in low- and middle-income settings $[31,32]$. In light of testing shortages, group testing (sample pooling, combining clinical specimens from multiple individuals into a single biological sample for a single RT-PCR test) has garnered attention as a diagnostically sensitive and resource-efficient alternative to individualbased testing [33-38].

In order to mitigate and prevent future nosocomial outbreaks, there is an urgent need to optimize COVID19 surveillance in long-term care settings, taking into account both the unique epidemiological characteristics of SARS-CoV-2 and limited availability of testing resources [1]. Here, we investigated the efficacy, timeliness, and resource efficiency of a range of COVID-19 surveillance strategies using simulations from a dynamic SARS-CoV2 transmission model that uses detailed inter-individual contact data to describe interactions between patients and staff in long-term care.

\section{Methods}

Simulating COVID-19 outbreaks in long-term care

We simulated nosocomial outbreaks of COVID-19 using a dynamic, stochastic, individual-based Susceptible Exposed Infectious Recovered (SEIR) model of SARS-CoV2 transmission coded in $\mathrm{C}++$ [39]. The model is described fully in Additional File 1 using the Overview, Design concepts, and Details (ODD) protocol for 
individual-based modelling [12, 18, 38-57]. The goals of our model are to simulate (i) dynamic inter-individual contacts among patients and staff in an LTCF setting, (ii) transmission of SARS-CoV-2 along simulated contact networks, and (iii) clinical progression of COVID-19 among individuals infected with SARS-CoV-2. Throughout, COVID-19 refers to any case of SARS-CoV-2 infection, and not only symptomatic cases.

\section{Characterizing LTCF structure, demographics, and inter- individual contact behaviour}

We used data from the i-Bird study to inform the population structure and dynamic inter-individual contact network used in our model. The i-Bird study has been described elsewhere $[41,58]$; briefly, close-proximity interactions were measured every $30 \mathrm{~s}$ by sensors worn by all patients and staff over a 17-week period in 2009 in a rehabilitation hospital in northern France. There were 170 patient beds across the five wards of this LTCF, and staff were distributed across 13 categories of employment, grouped here as HCWs (caregiver, nurse, physiotherapist, occupational therapist, nurse trainee, physician, and hospital porter) or ancillary staff (hospital services, administration, other rehabilitation staff, management, logistical staff, and activity coordinator/hairdresser) (Fig. 1a).

This population structure was used in our model, but a novel contact network was simulated to account for missing data resulting from imperfect sensor compliance in the raw contact network (Fig. 1b; described in Additional File 1). Real patient admission and staff timesheet data were used to determine who was present in the LTCF: there were on average 170 patients and 240 staff present each week, stratified by ward and type of individual (e.g. patient, nurse, logistical staff) in Additional File 2: Table S1. The probability of coming into contact with another individual at each model time-step (30 s) was estimated from the raw contact data and stratified by hour of the day (e.g. 8:00:00-8:59:30, 9:00:00-9:59:30), day of the week (weekday vs. weekend), ward and type of individual. At each time-step, new contacts were simulated based on these probabilities, and contact durations were drawn stochastically from log-normal distributions stratified by the same variables. Contact behaviours were comparable between the raw and simulated networks, and fidelity of the simulated network has been validated previously by its ability to reproduce transmission dynamics from a real outbreak of methicillin-resistant Staphylococcus aureus in this LTCF $[55,58]$.

\section{Characterizing SARS-CoV-2 transmission and COVID-19 infection}

Parameter estimates from the literature were used to characterize SARS-CoV-2 transmission and clinical progression of COVID-19 (see Additional File 1: Table S2). We assumed that susceptible patients and staff could become infected with SARS-CoV-2 if in direct contact with an infectious individual, with the probability of transmission depending on the duration of contact. Owing to a lack of data from healthcare settings, SARSCoV-2 transmissibility was estimated using data from the community (see Additional File 1). Assuming $R_{0}=3$ in France prior to lockdown [44], and using prepandemic inter-individual contact data [45], we derived a transmission probability per minute spent in contact with an infectious individual $p=0.14 \%$. Under baseline assumptions in our simulated LTCF, this estimate for $p$ resulted in a mean $R_{0}=4.04$ (Additional File 2: Fig. S1). This is consistent with the finding that, for any given value of $p, R_{0}$ is expected to vary between community and healthcare settings because of fundamental differences in inter-individual contact behaviour [43]. However, to reflect considerable uncertainty in the true value of $p$, we considered extreme values in sensitivity analysis ( $p=0.07 \%, 0.28 \%)$.

Clinical progression of COVID-19 was characterized by a modified SEIR process, with (i) a non-infectious exposed period of 2-5 days, (ii) an infectious presymptomatic period of 1-3 days, (iii) an on-average 7day infectious "symptomatic" period with three levels of symptom severity (severe, mild or asymptomatic), and (iv) eventual recovery with full immunity (Fig. 1c). Together, (i) and (ii) amount to an incubation period of 38 days including a 1-3-day window of pre-symptomatic transmission, consistent with estimates used elsewhere $[18,19,59]$. For (iii), we assumed that $70 \%$ of infected individuals develop clinical symptoms [51, 60, 61], 20\% of which develop severe/critical symptoms [52]. Durations for each stage of infection were drawn probabilistically from their respective distributions for each infection. We assumed no difference in average time to symptom onset for mild symptomatic and severe symptomatic cases. As surveillance strategies were evaluated only for detection of outbreaks, death and potential long-term clinical outcomes were not explicitly simulated. Each simulation began by introducing one nonsymptomatic index case (either exposed, presymptomatic or asymptomatic) into the facility on the first day of each simulation $(t=0)$. In the baseline scenario, both patients and staff introduced SARS-CoV-2 into the LTCF.

\section{Measuring outbreaks}

Simulated COVID-19 outbreaks were described using various outcome measures, including infection incidence, infection prevalence, case distribution (proportion of infections among patients, HCWs, and ancillary staff), outbreak size (cumulative number of cases after 12 


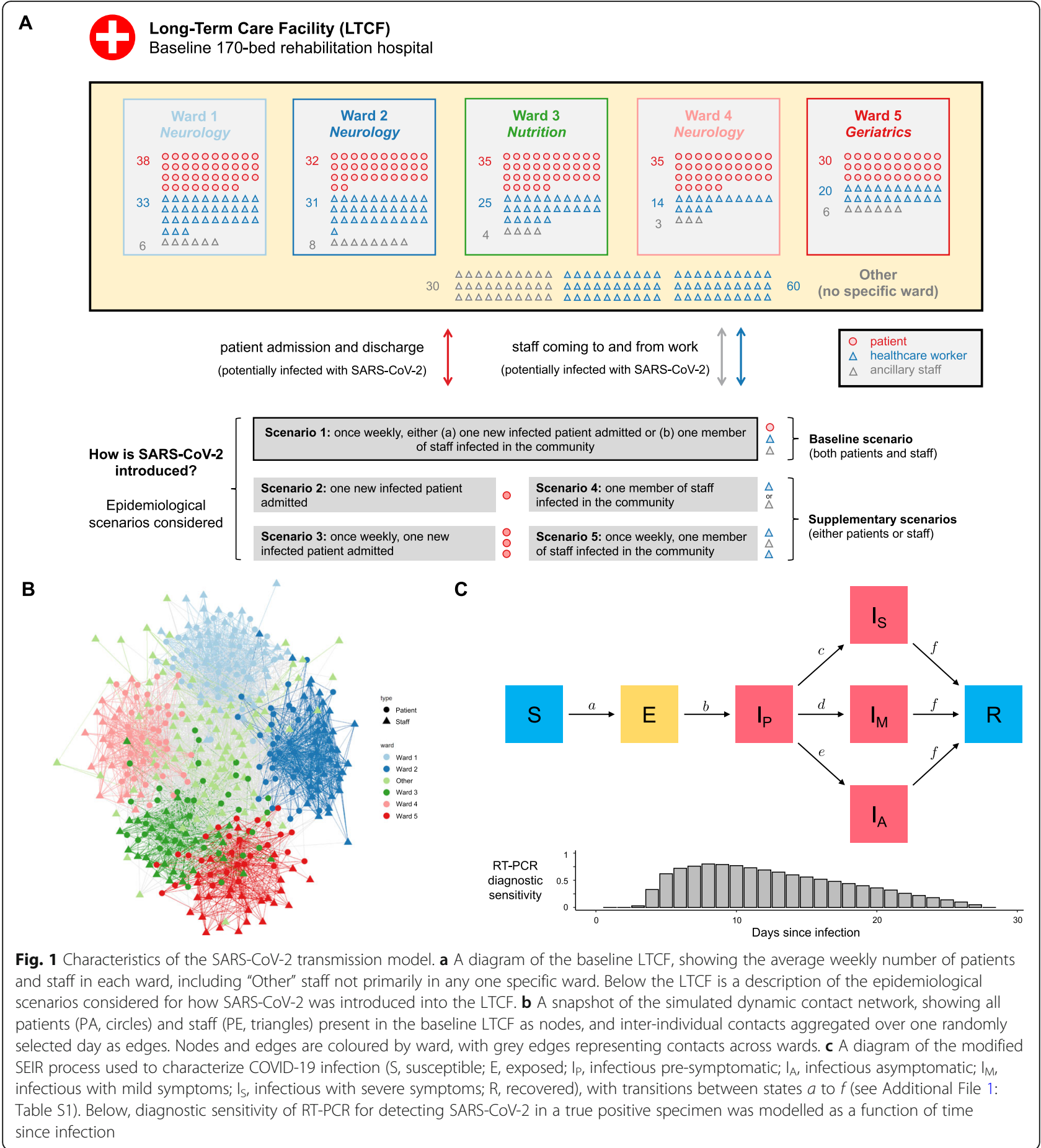

weeks of unmitigated transmission, the full duration of each outbreak simulation), and outbreak size upon first presentation of COVID-19 symptoms.

\section{Developing a COVID-19 surveillance algorithm}

We developed a stochastic surveillance algorithm to evaluate a range of surveillance strategies for their efficacy, timeliness, and resource-efficiency in detecting
COVID-19 outbreaks. Strategies varied according to who received conventional nasopharyngeal swabs and RT-PCR tests, and with what priority. Demographic and clinical indications were used to administer swabs and tests, beginning on the first day of each outbreak simulation and assuming a daily maximum testing capacity ranging from 1 to 32 tests/day. We assumed a 24-h lag from swab to test result, perfect specificity (true negative 
rate) and imperfect sensitivity (true positive rate). Using data from a meta-analysis of RT-PCR for detection of SARS-CoV-2 in upper respiratory samples, sensitivity was modelled as a function of time since infection, ranging from $0 \%$ on the first 2 days after infection, to $33 \%$ after 4 days, peaking at $80 \%$ after 8 days, and gradually decreasing thereafter (Additional File 1: Fig. S1) [54]. Each test result was determined stochastically according to these parameters. The algorithm is described in further detail in Additional File 1.

\section{Surveillance strategies considered}

Four types of surveillance were evaluated: (i) testing individuals with particular indications, (ii) random testing, (iii) testing cascades, and (iv) group testing (Table 1). Each was further divided into distinct surveillance strategies. For (i), three indications were considered: presentation of severe COVID-like symptoms (reference strategy), presentation of any COVID-like symptoms, or new admission to the LTCF. For (ii), tests were randomly distributed among patients, HCWs, or all patients and staff. In contrast to (i) and (ii), strategies (iii) and (iv) were conceived as hierarchical testing protocols, in which individuals presenting with severe COVID-like symptoms were always tested first to reflect their clinical priority. Remaining tests were subsequently allocated via cascades (iii) or as a single group test (iv).

For (iii), testing cascades were conceived as mixed testing strategies combining (i) and (ii), in which multiple indications were considered simultaneously but ordered according to their perceived clinical priority. If there were more tests available than individuals indicated for testing, remaining tests were distributed randomly among remaining patients, such that cascades always maximized daily testing capacity. For (iv), clinical specimens from individual swabs were pooled together and tested as one, up to a maximum of 32 swabs per test in the baseline analysis. Various studies have demonstrated the efficacy of this method for SARS-CoV-2 detection, with sufficient diagnostic accuracy to detect a single SARS-CoV-2-positive specimen pooled with $30+$ negative specimens $[38,62,63]$. Yet diluting positive specimens nonetheless reduces the concentration of viral RNA in the sample, which should reduce sensitivity of a group test compared to an individual test of the same positive specimen [64]. We estimated a $0.7 \%$ reduction in test sensitivity per additional negative specimen added to a group sample when assuming a typical RT-PCR Cycle threshold cut-off $(\mathrm{Ct}=40)$, and for sensitivity analysis estimated a faster rate $(1.3 \%)$ corresponding to a stricter threshold $(\mathrm{Ct}=35)$ (see Additional File 1).

Table 1 Surveillance strategies evaluated for detection of COVID-19 outbreaks in a LTCF. Strategies differ in how swabs and tests are apportioned to patients and staff. Arrows $\rightarrow$ indicate order of priority for testing cascades. Test, RT-PCR test; swab, nasopharyngeal swab; symptoms, COVID-like symptoms; admission, arrival of new patient to the LTCF

\begin{tabular}{|c|c|c|c|}
\hline $\begin{array}{l}\text { Surveillance } \\
\text { type }\end{array}$ & Description & Surveillance strategy & $\begin{array}{l}\text { Daily testing } \\
\text { capacity always } \\
\text { reached? }\end{array}$ \\
\hline \multirow{3}{*}{$\begin{array}{l}\text { Single } \\
\text { indication }\end{array}$} & \multirow{3}{*}{$\begin{array}{l}\text { Administer tests to any individuals indicated for testing, up to } \\
\text { the daily testing capacity. If the number of individuals indicated } \\
\text { exceeds the number of tests available, select randomly among } \\
\text { them. }\end{array}$} & Symptoms (severe) [reference strategy] & No \\
\hline & & Symptoms (any) & No \\
\hline & & Admission & No \\
\hline \multirow[t]{3}{*}{ Random } & \multirow{3}{*}{$\begin{array}{l}\text { Each day, randomly administer tests to individuals in a particular } \\
\text { demographic group. }\end{array}$} & Random (patients) & Yes \\
\hline & & Random (HCWs) & Yes \\
\hline & & Random (all: patients, HCWs and ancillary staff) & Yes \\
\hline \multirow[t]{4}{*}{ Cascade } & \multirow{4}{*}{$\begin{array}{l}\text { A combination of indications and random testing. First, } \\
\text { use indications to administer tests according to a given order } \\
\text { of priority. Then, if any tests remain, distribute them randomly } \\
\text { among patients not otherwise indicated for testing. }\end{array}$} & $\begin{array}{l}\text { Symptoms (severe) } \rightarrow \text { Symptoms (mild) } \rightarrow \\
\text { Random (patients) }\end{array}$ & Yes \\
\hline & & $\begin{array}{l}\text { Symptoms (severe) } \rightarrow \text { Symptoms (mild) } \rightarrow \\
\text { Admission } \rightarrow \text { Random (patients) }\end{array}$ & Yes \\
\hline & & $\begin{array}{l}\text { Symptoms (severe) } \rightarrow \text { Admission } \rightarrow \text { Random } \\
\text { (patients) }\end{array}$ & Yes \\
\hline & & $\begin{array}{l}\text { Symptoms (severe) } \rightarrow \text { Admission } \rightarrow \text { Symptoms } \\
(\text { mild }) \rightarrow \text { Random (patients) }\end{array}$ & Yes \\
\hline \multirow{4}{*}{$\begin{array}{l}\text { Group } \\
\text { testing }\end{array}$} & \multirow{4}{*}{$\begin{array}{l}\text { Classic two-stage sample pooling, modified to account for clinical } \\
\text { urgency of severe COVID-19. First, administer individual tests to } \\
\text { any patients or staff presenting with severe symptoms. Then, if } \\
\text { at least one test remains, pool clinical specimens together and } \\
\text { run one test across this group sample. If the test result is positive, } \\
\text { individually re-swab and re-test all included individuals to identify } \\
\text { cases. The maximum number of samples per group test was varied } \\
\text { from } 2 \text { to } 64 \text {. }\end{array}$} & Symptoms (any) & No \\
\hline & & Admission & No \\
\hline & & $\begin{array}{l}\text { Random (patients) (always maximizes number } \\
\text { of specimens per group test) }\end{array}$ & No \\
\hline & & $\begin{array}{l}\text { Random (HCWs) (always maximizes number } \\
\text { of specimens per group test) }\end{array}$ & No \\
\hline
\end{tabular}


Various group testing procedures have been proposed elsewhere [33, 34, 37, 65, 66]; here we evaluated a simple two-stage "Dorfman" protocol that does not require additional investment or infrastructure, but which requires all individuals included in the initial group test to be reswabbed and re-tested individually upon a positive group test result in order to determine which individual(s) is (are) infected [35, 67].

\section{Administering swabs and tests}

Each swab resulted in one RT-PCR test, except for group testing strategies, in which multiple swabs were combined per test. Admission-based tests were administered upon a patient's arrival to the LTCF, and symptom-based tests were administered on the first day that symptoms appeared. We further assumed that no individuals refused swabbing/testing. Clinically, COVID19 can resemble other common acute respiratory infections, such that individuals not infected with SARS$\mathrm{CoV}-2$ can nonetheless present with COVID-like symptoms and be indicated for symptom-based testing [68]. We used influenza-like illness as a proxy for COVID-like symptoms of aetiologies other than SARS-CoV-2. The daily incidence rate of influenza-like illness in our LTCF setting (1.1\%) was calculated using data from 2008 to 2017 from French emergency departments (OSCOUR network) as the daily incidence rate of influenza-like illness among older adults (50-99 years) [53]. As with actual COVID-19, we assumed that $20 \%$ of these individuals also present with severe symptoms.

\section{Surveillance outcomes evaluated}

Surveillance strategies were evaluated for their ability to detect COVID-19 outbreaks using four primary outcome measures: first, the probability of detecting an outbreak (i) at any time $t$ from the index case at $t=0$, (ii) prior to any secondary cases (interpreted as the probability of detecting the index case before any nosocomial transmission), or (iii) prior to first presentation of COVID-19 symptoms. Second, detection lag, the number of days from the index case to outbreak detection (first positive test result). For group testing, this was taken as the date of the first positive group test result (first round of testing) and not the date of subsequent case identification (second round). We defined a maximum detection lag of 22 days, after which all outbreaks were assumed to be detected regardless of the surveillance strategy used. Third, outbreak size upon detection, the cumulative number of cases at first positive test result. Fourth, the total number of (i) nasopharyngeal swabs used and (ii) RT-PCR tests conducted until outbreak detection. Here, for group testing, this does include the second round of testing, i.e. resources required to individually re-swab and re-test all individuals included in the initial positive group test.

\section{Measuring surveillance efficiency}

From a health-economic perspective, an efficient use of healthcare resources is one that yields better health outcomes than alternative uses of the same resources [69]. Efficiency can be measured using incremental analysis, in which the additional cost of a particular intervention compared to a reference baseline is scaled by its additional health benefit [70]. This is traditionally expressed as the incremental cost-effectiveness ratio using monetary costs and standardized units of health benefit (e.g. quality-adjusted life-years gained). To report on efficiency in terms of the surveillance cost and benefit outcomes measured in this study, we defined a similar metric, the incremental efficiency ratio (IER),

$$
\mathrm{IER}=\frac{(\text { surveillance resource use })_{S}-(\text { surveillance resource use })_{R}}{(\text { surveillance outcome })_{S}-(\text { surveillance outcome })_{R}},
$$

for each surveillance strategy $S$ relative to the reference $R$. Efficiency results were calculated using the IER as the number of additional swabs and tests required per 1case reduction in outbreak size upon detection (for simplicity, reported as mean additional swabs and tests used per case averted). Here, we took the perspective of an LTCF with a reference strategy of only testing individuals with severe COVID-like symptoms.

\section{Uncertainty and sensitivity analysis}

We ran a range of sensitivity analyses to account for uncertainty in (i) how SARS-CoV-2 was introduced into the LTCF, (ii) LTCF size and structure, (iii) transmissibility of SARS-CoV-2, and (iv) diagnostic sensitivity of RT-PCR for individual samples and (v) for group samples (see assumptions in Additional File 1). For each scenario, 100 epidemics were simulated using the transmission model. For each simulated epidemic, the surveillance algorithm was run 100 times across six testing capacities $(1,2,4,8,16$ or 32 tests/day), for a total 60,000 stochastic simulations for each surveillance strategy and each scenario. Across all scenarios, we also varied the maximum number of swabs potentially included per group test $(2,4,8,16,32$, or 64 swabs/test). Outcomes were only evaluated for epidemic simulations that resulted in nosocomial outbreaks, defined as simulations with $\geq 1$ new case of COVID-19 within 21 days of the initial index case. Unless stated otherwise, outcome measures are reported as median values across all simulations, with uncertainties expressed as 95\% uncertainty intervals, i.e. outcomes from the 2.5th and 97.5th percentiles. Supplementary results can be found in Additional File 2. 


\section{Results}

SARS-CoV-2 spreads quickly, but COVID-19 symptoms lag behind

SARS-CoV-2 spread quickly, but with a great degree of stochasticity upon its random introduction to simulated LTCFs (Fig. 2, Additional File 2: Fig. S2). After 3 weeks of unmitigated transmission, a cumulative 86 (95\% uncertainty interval 6-224) individuals were infected, predominantly other patients (median 72\%), then HCWs (25\%), and ancillary staff (3\%) (Additional File 2: Table S2). Outbreaks were characterized by a median lag of 9 (2-24) days between the non-symptomatic index case entering the LTCF and first presentation of mild COVID-19 symptoms among any patient or staff in the facility (Additional File 2: Table S3). By the time symptoms emerged, an additional 5 (0-29) individuals had acquired SARS-CoV-2 but were not (yet) showing symptoms (Additional File 2: Table S4). Lags were longer for first presentation of severe COVID-19 symptoms (15 days from index case, 4-28), coinciding with a greater cumulative number of secondary infections (25, 0-101).

\section{Less effective surveillance strategies allow infections to accumulate}

Surveillance strategies varied in their ability to detect emerging COVID-19 outbreaks. Surveillance efficacy depended on the stochastic nature of outbreaks, including how many, and which types of individuals became infected over time (Fig. 2c, d). Outbreaks grew exponentially at their outset, so delaying outbreak detection by just 1 or 2 days potentially coincided with tens more infections (Additional File 2: Fig. S3). Five days from the index case entering the LTCF, only 2 (1-12) individuals were infected; after 10 days, 9 (1-44) were infected; and after 15 days, $36(2-124)$ patients and staff were infected.

\section{Optimal surveillance depends on daily testing capacity}

Across all testing capacities, only testing individuals with severe COVID-like symptoms was among the least effective surveillance strategies considered (Fig. 3). This "reference" strategy took a median 16-17 days to detect outbreaks and had a $2-4 \%$ probability of detecting the initial index case prior to any secondary cases (Additional File 2: Fig. S4). Instead of only severe symptoms, testing individuals with any COVID-like symptoms was more effective, taking 9-15 days to detect outbreaks, with a $3-14 \%$ probability of detecting index cases prior to any secondary cases. Only testing patients at admission was overall ineffective by right of detecting neither staff index cases nor ongoing outbreaks already underway in the LTCF, resulting in long median delays to outbreak detection despite comparatively high probabilities of detecting COVID-19 prior to any secondary cases $(10-33 \%)$. In the scenario where only new patients introduced SARS-CoV-2 into the LTCF, there was a $34 \%$ probability of detecting the index case when testing all patients upon admission, or $66 \%$ in a sensitivity analysis considering higher and more stable RT-PCR sensitivity. For random testing strategies, surveillance was highly ineffective when few tests were available, but increasingly effective at higher testing capacities. Conversely, for indication-based strategies, efficacy plateaued when capacity exceeded the number of individuals indicated for testing (Additional File 2: Fig. S4).

At high testing capacity (16-32 tests/day, $\approx 9-19$ tests/100 beds/day), testing cascades were the most effective surveillance strategies. The four cascades considered here detected outbreaks within a median 7-10 days, coinciding with just 3-6 COVID-19 infections among all patients and staff. Cascades had a $19-36 \%$ chance of detecting outbreaks prior to any secondary cases, a 26$46 \%$ chance prior to the emergence of any COVID-19 symptoms, and a $64-85 \%$ chance prior to severe COVID-19 symptoms. Cascades that included both new patient admission and presentation of any COVID-like symptoms as indications for testing were most effective.

At low testing capacity ( 1 or 2 tests/day, $\approx 0.6-1.2$ tests/100 beds/day), group testing was the most effective form of surveillance considered. Compared to the reference (16-17 days) and cascades (16-17 days), outbreaks were detected within 11-14 days (coinciding with a cumulative 9-16 infections) when pooling random patients, or 12-14 days (15-23 infections) when pooling random HCWs. At this low capacity, it was also more effective to pool symptomatic individuals in group tests (10-12 days, 9-17 infections) than to test them individually (12-15 days, 17-27 infections) because individuals with non-COVID but COVID-like symptoms were also "in competition" for limited tests. Compared to the baseline protocol, which assumed a maximum of 32 swabs/ test, group testing was less effective given fewer swabs per test, despite potentially higher test sensitivity. For example, when pooling randomly selected patients in daily group tests, outbreaks were detected within 11-14 days at 32 swabs/test, $12-15$ days at 8-16 swabs/test, and 14-17 days at 2-4 swabs/test. In a sensitivity analysis considering a stricter RT-PCR diagnostic threshold $(\mathrm{Ct}=35$ instead of 40$)$, group testing was most effective at $16-32$ swabs per test (12-15 days), but declined substantially for greater group sample sizes (16-17 days at 64 swabs/test) (Additional File 2: Fig. S5).

\section{Group testing symptomatic individuals is the most efficient use of both swabs and tests}

Surveillance strategies varied considerably in their use of testing resources (Additional File 2: Fig. S6) and in their 


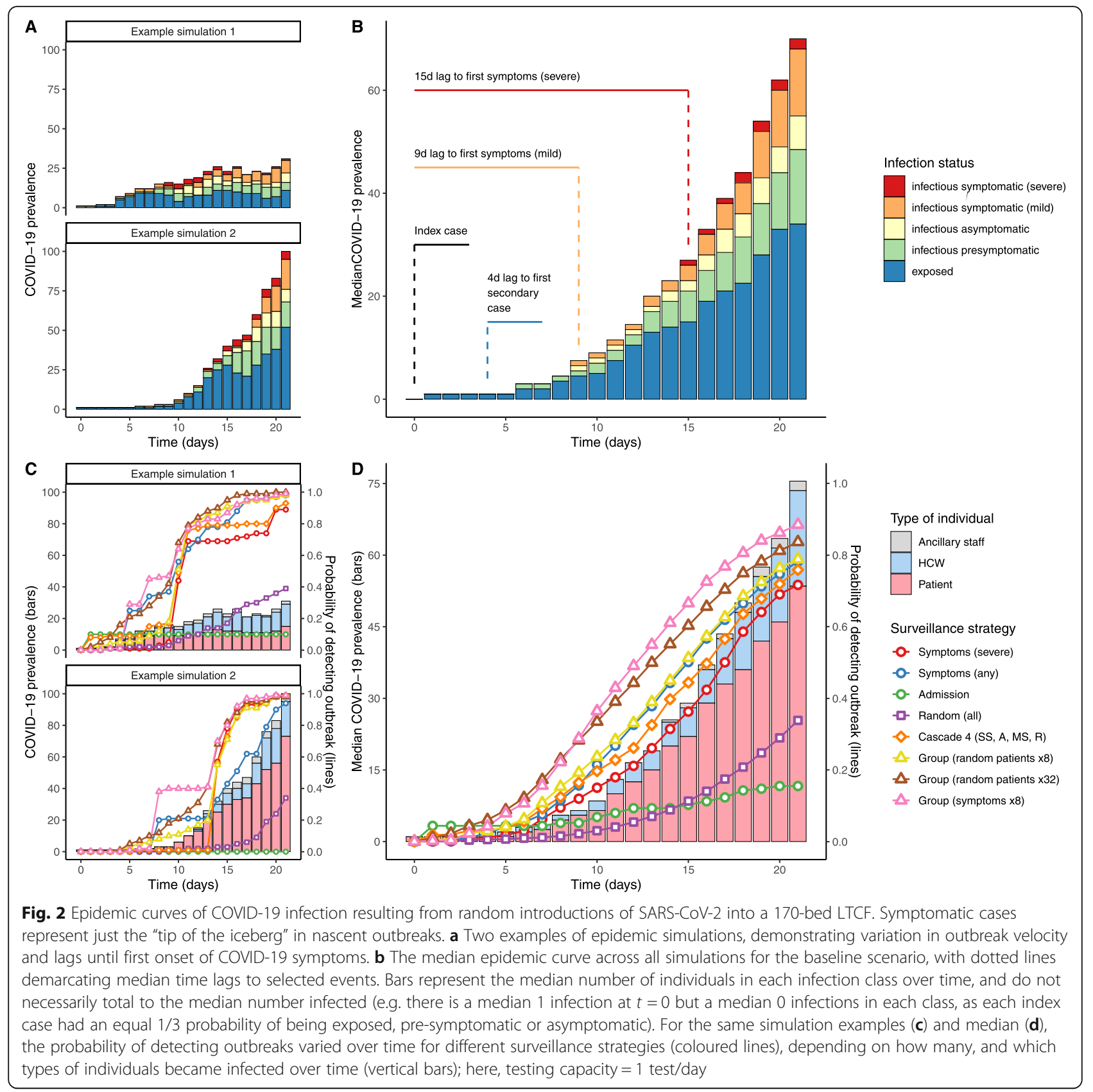

efficiency for improving COVID-19 outbreak detection relative to the reference strategy (Fig. 4). The reference used the fewest swabs and tests, on average $<1 /$ day regardless of the assumed daily testing capacity (owing to a low daily incidence of severe COVID-like symptoms). At high testing capacity (16-32 tests/day), the high incremental efficacy of cascades (outbreak detection a mean 5-8 days earlier than the reference, prior to $22-27$ additional infections) resulted from extensive resource use (104-276 additional tests and swabs), for mean efficiencies of 4.0-11.2 additional swabs and tests per case averted. Although simply testing all patients and staff with any COVID-like symptoms was less effective than using testing cascades, it was a more efficient means to improve surveillance (mean 1.3 additional tests per case averted).

Group testing strategies were generally efficient with respect to tests, but used highly variable numbers of swabs to detect outbreaks. At high swabbing capacity (16-32 swabs/group test, $\approx 9-19$ swabs/100 beds/day) and across all testing capacities, pooling randomly selected patients used a mean 11-38 excess tests to detect outbreaks 2-4 days earlier and prior to 14-21 additional infections (0.8-1.8 additional tests per case averted), but 


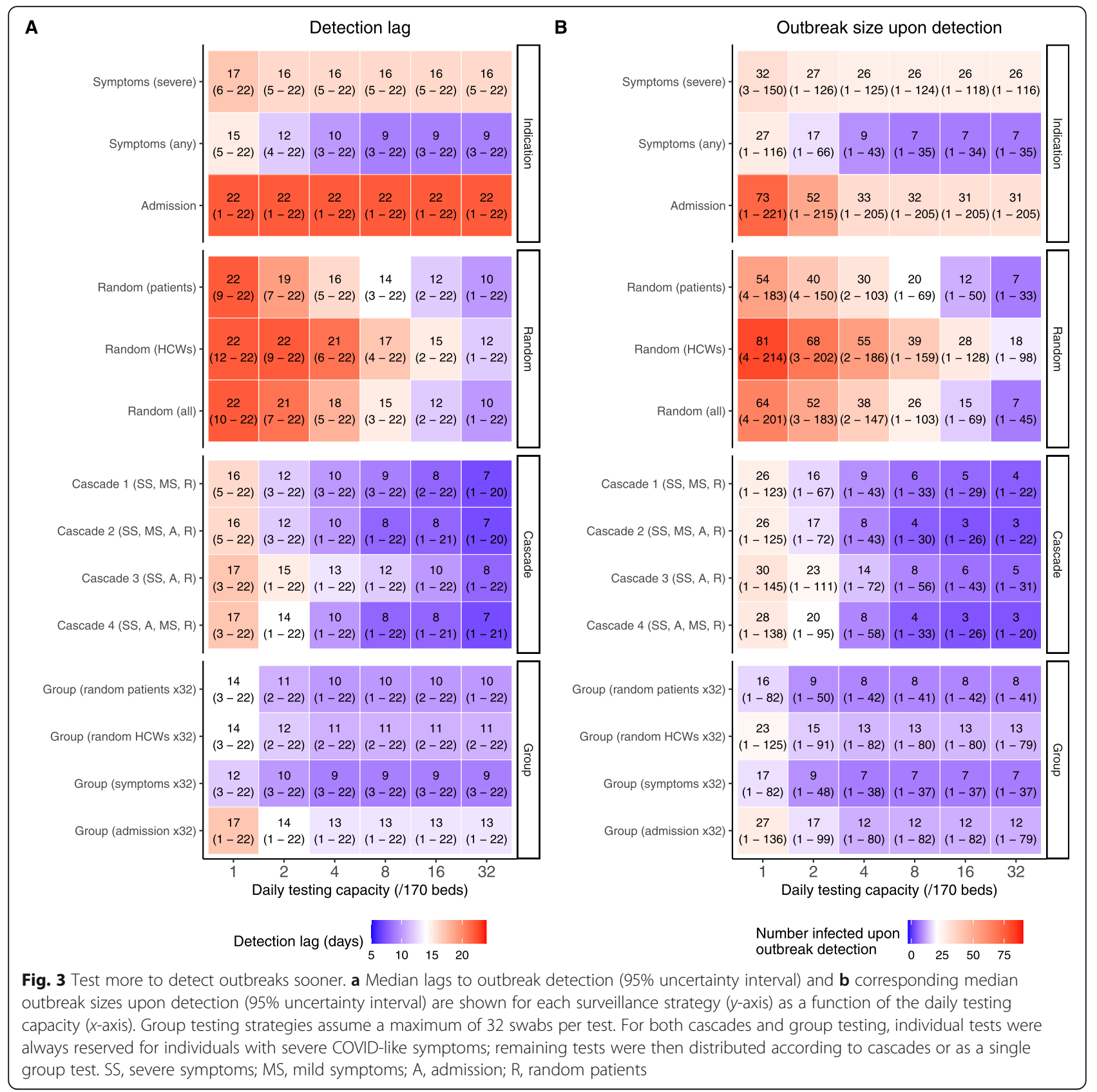

a median 94-384 additional swabs (6.7-18.7 additional swabs per case averted). Pooling the same number of randomly selected HCWs was less efficient than pooling patients (detection $=1-4$ days earlier, prior to 6-14 infections; efficiency $=1.3-2.8$ additional tests and 15.927.5 additional swabs per case averted). By contrast, for all scenarios and testing capacities considered, pooling individuals with any COVID-like symptoms was among the most efficient strategies in terms of both swabs and tests. In the most resource-limited scenarios (1-2 tests, $\approx 0.6-1.2$ tests/100 beds/day; $2-8$ swabs per group test, $\approx 1-5$ swabs/100 beds/day), this was both the most effective means to detect COVID-19 outbreaks and the most efficient means to improve surveillance from the reference (detection $=1-6$ days earlier, prior to $11-22$ additional infections; efficiency $=0.3-0.6$ additional tests and 1.0-1.3 additional swabs per case averted).

\section{Discussion}

The ongoing COVID-19 pandemic continues to devastate LTCFs worldwide, with high rates of mortality among particularly frail and elderly patients, and high rates of infection among patients and staff alike $[3,5,6,8]$. This motivates a need for timely and efficient surveillance 


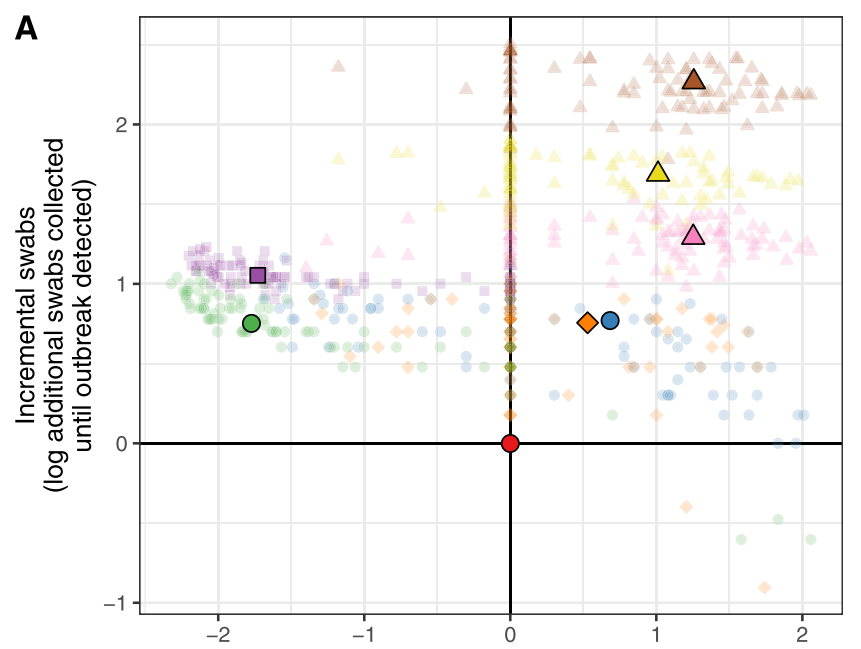
Surveillance strategy
- Symptoms (severe)
O Symptoms (any)
O Admission
$\square$ Random (all)
$\diamond$ Cascade 4 (SS, A, MS, R)
$\triangle$ Group (random patients $\times 8$ )
$\triangle$ Group (random patients $\times 32$ )
$\triangle$ Group (symptoms $x 8$ )

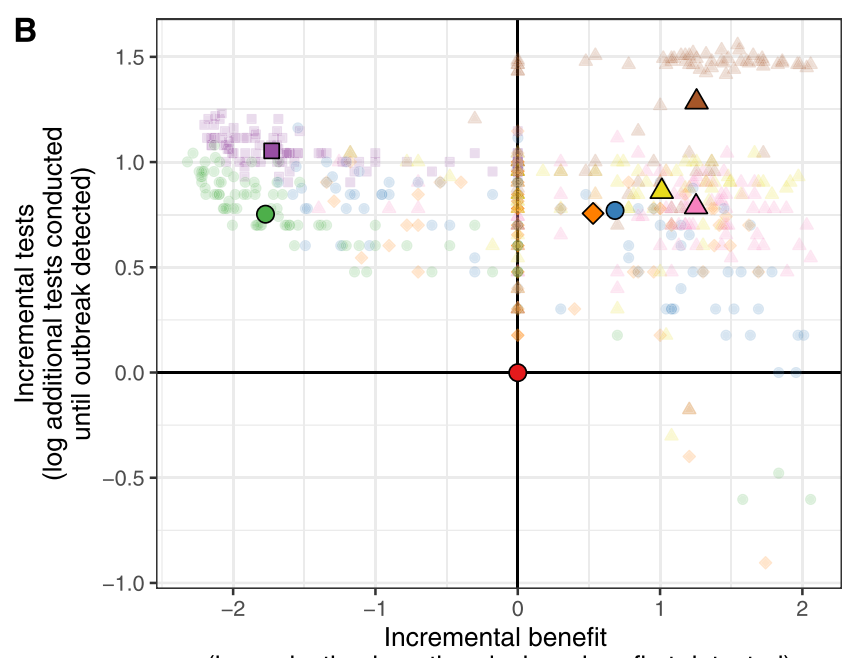

(log reduction in outbreak size when first detected)

Fig. 4 Incremental efficiency plots for selected surveillance strategies relative to a reference strategy of only testing individuals with severe COVID-like symptoms. Here, improvement in COVID-19 surveillance ( $x$-axis) is balanced against additional nasopharyngeal swabs used ( $y$-axis for a) and additional RT-PCR tests conducted ( $y$-axis for $\mathbf{b}$ ) until outbreaks were detected. Both axes are $\log _{10}$-adjusted. For both panels, daily testing capacity is fixed at 1 test/day (for higher testing capacities, see Additional File 2: Fig. S7). Small translucent points represent median outcomes across 100 surveillance simulations for each simulated outbreak, and larger opaque points represent mean of medians across all outbreaks

strategies that optimize limited testing resources to detect emerging outbreaks as quickly as possible. We used an individual-based transmission model to simulate COVID19 outbreaks in LTCF settings and evaluated a range of testing strategies for their efficacy and efficiency in detecting these outbreaks across various epidemiological assumptions and scenarios.

Our findings suggest that LTCFs can detect emerging COVID-19 outbreaks most quickly by using testing cascades, provided that they have substantial daily testing capacity (on the order of at least 1 test/10 beds/day). The most effective cascades considered multiple indications, including both COVID-like symptoms and patient admission, and detected outbreaks days ahead of traditional symptom-based screening and prior to the accumulation of additional infections. By extension, cascades had the greatest probability of identifying nonsymptomatic cases, a known challenge for COVID-19 surveillance in real LTCF settings [1]. These findings held in sensitivity analyses considering outbreaks in a smaller, 30-bed geriatric LTCF (Additional File 2: Fig. S8), as well as when halving or doubling SARS-CoV-2 transmissibility (Additional File 2: Figs. S9, S10). Although only a select few indications were considered in the present study, LTCFs may consider a wider range of known risk factors for SARS-CoV-2 acquisition in their own cascades to maximize the probability of detecting emerging outbreaks before widespread transmission.

COVID-19 surveillance was less effective in resourcelimited settings because of an inability to regularly test 
large numbers of patients and staff. In our analysis, group testing was the most effective means of COVID19 surveillance under limited testing capacity, and across all epidemiological scenarios and capacities was the most resource-efficient means to improve surveillance with respect to a "bare minimum" reference of only testing individuals with severe COVID-like symptoms. Even when assuming strict diagnostic cut-offs in sensitivity analysis, group testing strategies remained effective up to a maximum of 32 swabs per test (Additional File 2: Fig. S5). This broadly agrees with modelling results suggesting that group testing could be cost-effective for screening in large populations, as well as empirical evidence for the efficiency of group testing for COVID-19 surveillance in nursing homes [33, 71]. As with cascades, LTCFs that conduct group testing may consider a wider range of indications than was possible to include in this study, in order to maximize the probability of including potentially infected patients and staff in routine group tests. These findings reinforce current guidance from the World Health Organization, endorsing sample pooling to increase COVID-19 diagnostic capacity when testing demand outstrips supply, but cautioning against its use for contact tracing or in high-prevalence settings [63]. This is consistent with its implementation in the present study, as a means of surveillance in resource-limited long-term care settings without known active cases, but which are nonetheless susceptible to outbreaks.

Our analysis was limited to classical two-stage group testing, initially proposed by Dorfman in 1943 for syphilis screening among World War II soldiers [67], in which all individuals in a positive group test are individually re-tested to determine who is infected. This is regarded as the most straightforward approach [35], and we conservatively assumed re-swabbing in addition to re-testing of all individuals in a positive group test to account for potential logistical challenges of storing and maintaining large numbers of swabs for re-testing. Various alternative group testing strategies have been proposed and implemented elsewhere, including the use of simultaneous multi-pool samples, non-adaptive pooling schemes, and others $[35,37,65,66]$. These have the advantage of not requiring separate re-testing of all individuals in a positive group test and are hence more efficient in terms of the number of tests required for case identification. However, these strategies may also require additional testing infrastructure and expertise, which may be cost-prohibitive for the resource-limited settings that may benefit most from group testing in the first place. Decision-makers must consider trade-offs between the various costs and benefits of different group testing technologies, including how many individuals to include per test, how many stages of testing to conduct, and other potential logistical challenges [63].
We predicted that silent introductions of SARS-CoV-2 led to large outbreaks in the absence of specific control strategies. This is consistent with large COVID-19 outbreaks observed in LTCFs worldwide $[6,8,10,16]$, including an infamous outbreak in early 2020 in King County, Washington that resulted in 167 confirmed infections within 3 weeks of the first reported case [5]. We further predicted that larger proportions of patients became infected than staff, consistent with emerging evidence of higher SARS-CoV-2 incidence in patients than staff across LTCF settings worldwide [3, 8]. We also predicted larger and more rapid outbreaks when SARSCoV-2 was introduced through admission of an infected patient, rather than through a member of staff infected in the community, with important implications for surveillance efficacy (Additional File 2: Fig. S11). These findings are likely due to the nature of human interactions in the LTCF upon which we based our model, in which patient-patient contacts were particularly long and numerous [41]. Overall, these findings reinforce both (i) a need to screen incoming patients potentially exposed to or infected with SARS-CoV-2 [72] and (ii) the importance of interventions to limit contact between patients (e.g. social distancing among retirement home residents), as already widely recommended for affected facilities in the current pandemic context [4].

Simulated outbreaks were further characterized by delays between silent introduction of SARS-CoV-2 and first onset of COVID-19 symptoms, during which time new infections not (yet) showing symptoms accumulated. This is consistent with reported transmission dynamics of SARS$\mathrm{CoV}-2$; for instance, modelling studies have estimated that $30-57 \%$ of secondary infections among identified transmission pairs resulted from pre-symptomatic transmission [49], and that, early on in COVID-19 outbreaks in Singapore and Tianjin, pre-symptomatic transmission accounted for at least $65 \%$ of all transmission events [19]. Findings are also consistent with high proportions of asymptomatic infection, and important roles for presymptomatic and asymptomatic transmission reported in various LTCF outbreaks [5, 16, 21, 26-29]. The often silent nature of SARS-CoV-2 transmission highlights epidemiological challenges associated with screening for emerging outbreaks using symptoms alone. In addition to the strategies highlighted above, we found that testing patients and healthcare workers with any and not only severe COVID-like symptoms can substantially improve outbreak detection, supporting recommendations to expand testing criteria in LTCFs to include individuals with atypical signs and symptoms of COVID-19, such as muscle aches, sore throat, and chest pain [72].

A strength of the present study is the use of highly detailed inter-individual contact data to inform our individual-based transmission model. This allowed for 
recreation of life-like interaction dynamics among and between LTCF patients and staff and facilitated simulation of more realistic SARS-CoV-2 dissemination than a traditional mass-action transmission process. We are aware of no other studies using detailed individual-level contact networks to simulate SARS-CoV-2 transmission in healthcare settings, nor of studies using transmission modelling to evaluate COVID-19 surveillance strategies for emerging outbreaks.

Previous studies of COVID-19 surveillance have largely focused on the ability of testing strategies to mitigate ongoing SARS-CoV-2 transmission in active outbreak settings [73]. In particular, contact tracing has been identified as a highly effective form of surveillance, by targeting testing and isolation interventions to individuals at high risk of infection [74, 75]. However, these findings have limited relevance for emerging outbreaks, where active SARS-CoV-2 infection and ongoing transmission are not yet known. For healthcare facilities vulnerable to SARS-CoV-2 introductions, specific surveillance strategies are required for initial outbreak detection, in order to alert healthcare professionals and decision-makers to the presence of the virus in their institutions. Only then can proven measures like contact tracing and case isolation be implemented. By targeting this important epidemiological context, our findings complement an existing evidence base that has until now largely focused on how to control outbreaks that are already detected and well underway.

This work has several limitations. First, substantial uncertainties remain regarding epidemiological characteristics of COVID-19. It is well established that various COVID-19 outcomes vary with age, comorbidity, and frailty [76-78], but quantitative descriptions of these associations are incomplete, and it was not possible to reliably integrate such individual-level variation into our model. For instance, owing to individual-level risk factors, higher rates of symptomatic infection may be expected among LTCF residents than staff. Yet an outbreak investigation across six London care homes experiencing COVID-19 outbreaks estimated similar rates of asymptomatic infection in patients and staff and found no association with age [79], while the metaanalysis used to inform asymptomatic infection in our work highlighted poor reporting of age in included studies, precluding quantification of its relationship to COVID-19 symptom risk [51]. Nonetheless, calibrating model parameters to individual-level risk factors would facilitate more realistic simulations, and accounting for potentially higher rates of severe infection among older and frailer individuals could result in improved performance of symptom-based surveillance, including corresponding cascades and group testing strategies. This distinction may be particularly relevant for hospices, nursing homes, and other LTCFs with particularly frail populations; however, patients in the present rehabilitation hospital population were relatively young (median 58 years, IQR 47-72), limiting potential impacts of agestratified disease progression in this study.

Other epidemiological uncertainties that we were unable to account for include temporal variability in SARSCoV-2 transmissibility over the infectious period, individual-level variation in transmissibility, and a potential role for environmental acquisition [80, 81], although recent evidence suggests the former may be of limited relevance [82]. Further, most LTCFs have already implemented control measures, such as interruption of social activities and provisioning of personal protective equipment, that should act to reduce transmission from baseline. We conducted sensitivity analyses to consider unusually high and low transmission rates to reflect these uncertainties. Although SARS-CoV-2 spread more or less quickly, the relative efficacies of surveillance strategies were largely unchanged in these analyses, resulting in the same conclusions for optimizing use of limited testing resources to detect COVID-19 outbreaks (Additional File 2: Figs. S9, S10, S12, S13).

Second, LTCFs represent a diverse range of healthcare institutions, each with unique specializations, patient populations and living conditions, and the generalizability of our findings across these settings is not clear. In a sensitivity analysis, we restricted simulations to the 30-bed geriatric ward to approximate a smaller LTCF geared towards elder care, with an average 8.0 daily patient-patient contacts and 8.3 daily patientstaff contacts. This compares to patterns observed in a nursing home in Paris (5.0 daily patient-patient contacts, 6.3 daily patient-staff contacts) [83], and corresponding results may better reflect a nursing home environment than the baseline analysis. In this much smaller facility, high testing and swabbing capacities approximated universal testing strategies, in which large proportions of individuals were routinely tested. This explains why randomly testing among all individuals was among the most effective strategies at highest testing capacity (Additional File 2: Fig. S8), and why pooling even relatively small numbers of randomly selected individuals was a particularly efficient strategy in this setting (Additional File 2: Fig. S14). Otherwise, overall conclusions for surveillance were similar to the baseline LTCF.

Finally, the testing landscape for COVID-19 is due to shift quickly, with increased testing capacity and alternative testing technologies, such as rapid diagnostic tests, likely to become increasingly available in the coming months and years. However, uptake of new technologies is certain to be heterogeneous, and testing resources may remain limited for the foreseeable future, particularly in low- and middle-income settings [31, 32]. To 
reflect a scenario with more effective testing technology, in a sensitivity analysis, we assumed higher and more stable RT-PCR sensitivity over the course of infection. In this analysis, qualitative surveillance conclusions were again unchanged from the main analysis, although testing patients upon LTCF admission was notably more effective than in the main analysis (Additional File 2: Fig. S15). Although we explicitly modelled standard RT-PCR testing throughout this study, our findings may be broadly generalizable to other COVID-19 testing technologies with limited capacity. Findings for group testing, however, necessarily assume that pooling clinical samples is both logistically feasible and retains sufficient diagnostic sensitivity, as demonstrated for RT-PCR and SARS-CoV-2. Further, even in settings with abundant testing capacity, limiting the number of tests necessary to detect an outbreak will remain a priority given healtheconomic concerns.

\section{Conclusions}

In conclusion, our findings demonstrate the susceptibility of LTCFs to large COVID-19 outbreaks, as well as epidemiological challenges associated with COVID-19 surveillance. We found that testing cascades, which combine clinical indications and random testing, are a highly effective means to detect emerging outbreaks given ample testing resources. For resource-limited settings unable to routinely screen large numbers of individuals, however, group testing is preferable, both more effective and resource-efficient than cascades and other considered strategies. These findings add to a limited evidence base for optimizing COVID-19 surveillance in healthcare institutions. Even in regions where non-pharmaceutical interventions have come to slow transmission in the community, LTCFs remain uniquely vulnerable to COVID-19. Increasing testing capacity and expanding surveillance beyond symptombased screening could allow for earlier outbreak detection, facilitating timely intervention to limit transmission and save lives.

\section{Supplementary information}

The online version contains supplementary material available at https://doi. org/10.1186/s12916-020-01866-6.

Additional file 1: Supplementary Methods. (1) Data used to inform the model: Table S1. model transitions; Table S2. model parameters. (2) ODD protocol for individual-based modelling. (3) Description of the surveillance algorithm: Figure S1. RT-PCR sensitivity over time; Figure S2. RT-PCR sensitivity for pooled samples with a single positive specimen; Figure S3. RT-PCR sensitivity for pooled samples with multiple positive specimens.

Additional file 2: Supplementary Results. (1) LTCF demography: Table S1. Patient and staff population structure by ward. (2) COVID-19 outbreak characteristics: Table S2. cumulative outbreak size over time; Table S3. Time lags to first COVID-19 symptom onset; Table S4 - cumulative outbreak size upon first COVID-19 symptom onset; Figure S1. Simulated $R_{0}$ distributions; Figure S2. comparing outbreak characteristics across five SARS-CoV-2 introduction scenarios. (3) Additional surveillance results: Figure S3. Relationship between detection lag and outbreak size upon detection; Figure S4. Probabilities of detecting outbreaks before nosocomial transmission and symptom onset; Figure S5. Comparing group testing efficacy in baseline and sensitivity analyses; Figure S6. Efficacy and resource use for selected surveillance strategies; Figure S7. incremental efficiency plots at high testing capacity; Figure S8. surveillance efficacy heatmaps for a 30-bed geriatric LTCF; Figure S9. surveillance efficacy heatmaps given a low SARS-CoV-2 transmission rate; Figure S10. surveillance efficacy heatmaps given a high SARS-CoV-2 transmission rate; Figure S11. the impacts of different routes of SARSCoV-2 introduction and daily testing capacity on surveillance efficacy; Figure S12. incremental efficiency plots given a low SARS-CoV-2 transmission rate; Figure S13. incremental efficiency plots given a high SARSCoV-2 transmission rate; Figure S14. incremental efficiency plots for a 30-bed geriatric LTCF; Figure S15. surveillance efficacy heatmaps given higher and more stable RT-PCR sensitivity.

\section{Abbreviations}

COVID-19: Coronavirus disease 2019; HCW: Healthcare worker; IER: Incremental efficiency ratio; LTCF: Long-term care facility; $R_{0}$ : Basic reproduction number; RT-PCR: Reverse transcriptase polymerase chain reaction; SARS-CoV-2: Severe acute respiratory syndrome coronavirus 2; SEIR: Susceptible Exposed Infectious Recovered; UK: United Kingdom; USA: United States of America

\section{Acknowledgements}

This work resulted from the MOD-COV Project (Modelling of the hOspital Dissemination of SARS-CoV-2), a collaboration between the Institut Pasteur, the Conservatoire Nationale des Arts et Métiers, and the AVIESAN/REACTing working group "Modelling SARS-CoV-2 dissemination in healthcare settings", whose members we thank (Niccolo Buetti, Christian Brun-Buisson, Sylvie Burban, Simon Cauchemez, Guillaume Chelius, Anthony Cousien, Pascal Crepey, Vittoria Colizza, Christel Daniel, Aurélien Dinh, Pierre Frange, Eric Fleury, Antoine Fraboulet, Marie-Paule Gustin, Lidia Kardas-Sloma, Elsa Kermorvant, Jean Christophe Lucet, Chiara Poletto, Rodolphe Thiebaut, Sylvie van der Werf, Philippe Vanhems, Linda Wittkop, Jean-Ralph Zahar).

We also thank the i-Bird Study Group (Anne Sophie Alvarez, Audrey Baraffe, Mariano Beiró, Inga Bertucci, Pierre-Yves Boëlle, Camille Cyncynatus, Florence Dannet, Marie Laure Delaby, Pierre Denys, Matthieu Domenech de Cellès, Eric Fleury, Antoine Fraboulet, Jean-Louis Gaillard, Boris Labrador, Jennifer Lasley, Christine Lawrence, Judith Legrand, Odile Le Minor, Caroline Ligier, Lucie Martinet, Karine Mignon, Catherine Sacleux, Jérôme Salomon, Thomas Obadia, Marie Perard, Laure Petit, Laeticia Remy, Anne Thiebaut, Damien Thomas, Philippe Tronchet, Isabelle Villain), as well as Jacob Barrett for helpful discussion.

\section{Authors' contributions}

LO and LT conceived the study. AD programmed the transmission model. DS programmed the surveillance algorithm, analysed the data, and presented results. DS, AD, LO, and LT interpreted the results. KP, BTH, DG, and JF consulted on analyses. DS wrote the manuscript. The authors edited and revised the manuscript. The authors read and approved the final manuscript.

\section{Funding}

The work was supported directly by internal resources from the French National Institute for Health and Medical Research, the Institut Pasteur, the Conservatoire National des Arts et Métiers, and the University of VersaillesSaint-Quentin-en-Yvelines/University of Paris-Saclay. This study received funding from the French Government's "Investissement d'Avenir" programme, Laboratoire d'Excellence "Integrative Biology of Emerging Infectious Diseases" (Grant ANR-10-LABX-62- IBEID). DS is supported by a Canadian Institutes of Health Research Doctoral Foreign Study Award (Funding Reference Number 164263) as well as the French government through its National Research Agency project SPHINX-17-CE36-0008-01. KP is supported by the National Institute for Health Research (NIHR) Health Protection Research Unit in Healthcare Associated Infections and Antimicrobial Resistance at the 
University of Oxford in partnership with Public Health England (grant number NIHR200915).

\section{Availability of data and materials}

The datasets used and/or analysed during the current study are available from the corresponding author on reasonable request.

\section{Ethics approval and consent to participate}

This study used inter-individual contact data from the i-Bird study, which obtained all authorizations in accordance with French regulations regarding medical research and information processing. All French IRB-equivalent agencies accorded the i-Bird programme official approval (CPP 08061; Afssaps 2008-A01284-51; CCTIRS 08.533; CNIL AT/YPA/SV/SN/GDP/AR091118 $N^{\circ}$ 909036). Signed consent by patients and staff was not required according to the French Ethics Committee to which the project was submitted.

\section{Consent for publication}

Not applicable.

\section{Competing interests}

LO reports grants from Pfizer, outside the submitted work. All other authors report no competing interests.

\section{Author details}

${ }^{1}$ Institut Pasteur, Epidemiology and Modelling of Antibiotic Evasion (EMAE), Paris, France. ${ }^{2}$ Université Paris-Saclay, UVSQ, Inserm, CESP, Anti-infective evasion and pharmacoepidemiology team, Montigny-Le-Bretonneux, France. ${ }^{3}$ Modélisation, épidémiologie et surveillance des risques sanitaires (MESURS), Conservatoire national des arts et métiers, Paris, France. ${ }^{4}$ Health Economics Research Centre, Nuffield Department of Population Health, University of Oxford, Oxford, UK. ${ }^{5}$ The National Institute for Health Research (NIHR) Health Protection Research Unit in Healthcare Associated Infections and Antimicrobial Resistance, University of Oxford, Oxford, UK. ${ }^{6}$ AP-HP, Paris Saclay, Public Health, Medical Information, Clinical Research, Le Kremlin-Bicêtre, France. ${ }^{7}$ Clinique de soins de suite et réadaptation, Choisy-Le-Roi, France. ${ }^{8}$ PACRI unit, Institut Pasteur, Conservatoire national des arts et métiers, Paris, France.

Received: 21 August 2020 Accepted: 23 November 2020

\section{Published online: 08 December 2020}

\section{References}

1. World Health Organization. Preventing and managing COVID-19 across long-term care services: policy brief. Geneva: World Health Organization; 2020.

2. Zhou F, Yu T, Du R, Fan G, Liu Y, Liu Z, et al. Clinical course and risk factors for mortality of adult inpatients with COVID-19 in Wuhan, China: a retrospective cohort study. Lancet. 2020;395:1054-62. https://doi.org/10. 1016/S0140-6736(20)30566-3.

3. Salcher-Konrad M, Jhass A, Naci H, Tan M, El-Tawil Y, Comas-Herrera A COVID-19 related mortality and spread of disease in long-term care: a living systematic review of emerging evidence. medRxiv. 2020. https://doi.org/10. 1101/2020.06.09.20125237.

4. D'Adamo H, Yoshikawa T, Ouslander JG. Coronavirus disease 2019 in geriatrics and long-term care: the ABCDs of COVID-19. J Am Geriatr Soc. 2020;68:912-7. https://doi.org/10.1111/jgs.16445.

5. McMichael TM, Currie DW, Clark S, Pogosjans S, Kay M, Schwartz NG, et al. Epidemiology of Covid-19 in a long-term care facility in King County, Washington. N Engl J Med. 2020;382:2005-11. https://doi.org/10.1056/ NEJMoa2005412.

6. Fisman D, Lapointe-Shaw L, Bogoch I, McCready J, Tuite A. Failing our most vulnerable: COVID-19 and long-term care facilities in Ontario. medRxiv. 2020. https://doi.org/10.1101/2020.04.14.20065557.

7. Fisman DN, Bogoch I, Lapointe-Shaw L, McCready J, Tuite AR. Risk factors associated with mortality among residents with coronavirus disease 2019 (COVID-19) in long-term care facilities in Ontario, Canada. JAMA Netw Open. 2020;3:e2015957. https://doi.org/10.1001/jamanetworkopen.2020.15957.

8. ECDC Public Health Emergency Team, Danis K, Fonteneau L, Georges S, Daniau C, Bernard-Stoecklin S, et al. High impact of COVID-19 in long-term care facilities, suggestion for monitoring in the EU/EEA, May 2020. Euro Surveill. 2020;25. https://doi.org/10.2807/1560-7917.ES.2020.25.22.2000956.
9. Bakaev I, Retalic T, Chen H. Universal testing-based response to COVID-19 outbreak by a long-term care and post-acute care facility. J Am Geriatr Soc. 2020;68:E38-9. https://doi.org/10.1111/jgs.16653.

10. Iritani O, Okuno T, Hama D, Kane A, Kodera K, Morigaki K, et al. Clusters of COVID-19 in long-term care hospitals and facilities in Japan from 16 January to 9 May 2020. Geriatr Gerontol Int. 2020;20:715-9. https://doi.org/10.1111/ ggi.13973.

11. Sanchez GV, Biedron C, Fink LR, Hatfield KM, Polistico JMF, Meyer MP, et al. Initial and repeated point prevalence surveys to inform SARS-CoV-2 infection prevention in 26 skilled nursing facilities - Detroit, Michigan, March-May 2020. MMWR Morb Mortal Wkly Rep. 2020;69:882-6. https://doi. org/10.15585/mmwr.mm6927e1.

12. Böger B, Fachi MM, Vilhena RO, Cobre A de F, Tonin FS, Pontarolo R. Systematic review with meta-analysis of the accuracy of diagnostic tests for COVID-19. Am J Infect Control. 2020. https://doi.org/10.1016/j.ajic.2020.07. 011.

13. Ministère des solidarités et de la santé. Recommandations pour le secteur SSR dans le contexte de l'épidémie COVID-19. 2020.

14. Rijksinstituut voor Volksgezondheid en Milieu. Inzet en testbeleid medewerkers verpleeghuizen, woonzorgcentra en kleinschalige woonvormen. 2020.

15. Department of Health \& Social Care. Admission and care of residents during COVID-19 incident in a care home. 2020.

16. Arons MM, Hatfield KM, Reddy SC, Kimball A, James A, Jacobs JR, et al. Presymptomatic SARS-CoV-2 infections and transmission in a skilled nursing facility. N Engl J Med. 2020;382:2081-90. https://doi.org/10.1056/ NEJMoa2008457.

17. Li W, Su YY, Zhi SS, Huang J, Zhuang CL, Bai WZ, et al. Virus shedding dynamics in asymptomatic and mildly symptomatic patients infected with SARS-CoV-2. Clin Microbiol Infect. 2020. https://doi.org/10.1016/j.cmi.2020.07.008.

18. Lauer SA, Grantz KH, Bi Q, Jones FK, Zheng Q, Meredith HR, et al. The incubation period of coronavirus disease 2019 (COVID-19) from publicly reported confirmed cases: estimation and application. Ann Intern Med. 2020;172:577-82. https://doi.org/10.7326/M20-0504.

19. Tindale LC, Stockdale JE, Coombe M, Garlock ES, Lau WYV, Saraswat M, et al. Evidence for transmission of COVID-19 prior to symptom onset. Elife. 2020;9. https://doi.org/10.7554/eLife.57149.

20. Huff HV, Singh A. Asymptomatic transmission during the COVID-19 pandemic and implications for public health strategies. Clin Infect Dis. 2020. https://doi.org/10.1093/cid/ciaa654.

21. Moghadas SM, Fitzpatrick MC, Sah P, Pandey A, Shoukat A, Singer BH, et al. The implications of silent transmission for the control of COVID-19 outbreaks. Proc Natl Acad Sci U S A. 2020. https://doi.org/10.1073/pnas. 2008373117.

22. Asad H, Johnston C, Blyth I, Holborow A, Bone A, Porter L, et al. Health care workers and patients as Trojan Horses: a COVID19 ward outbreak. Infection Prevention in Practice. 2020;:100073. https://doi.org/10.1016/j.infpip.2020. 100073.

23. Kimball A, Hatfield KM, Arons M, James A, Taylor J, Spicer K, et al. Asymptomatic and presymptomatic SARS-CoV-2 infections in residents of a long-term care skilled nursing facility - King County, Washington, March 2020. MMWR Morb Mortal Wkly Rep. 2020;69:377-81. https://doi.org/10. 15585/mmwr.mm6913e1.

24. Blackman C, Farber S, Feifer RA, Mor V, White EM. An illustration of SARSCoV-2 dissemination within a skilled nursing facility using heat maps. J Am Geriatr Soc. 2020. https://doi.org/10.1111/jgs.16642.

25. Gandhi M, Yokoe DS, Havlir DV. Asymptomatic transmission, the Achilles' heel of current strategies to control Covid-19. N Engl J Med. 2020;382:215860. https://doi.org/10.1056/NEJMe2009758.

26. Bigelow BF, Tang O, Barshick B, Peters M, Sisson SD, Peairs KS, et al. Outcomes of universal COVID-19 testing following detection of incident cases in 11 long-term care facilities. JAMA Intern Med. 2020. https://doi.org/ 10.1001/jamainternmed.2020.3738.

27. Louie JK, Scott HM, DuBois A, Sturtz N, Lu W, Stoltey J, et al. Lessons from mass-testing for COVID-19 in long term care facilities for the elderly in San Francisco. Clin Infect Dis. 2020. https://doi.org/10.1093/cid/ciaa1020.

28. Black JRM, Bailey C, Przewrocka J, Dijkstra KK, Swanton C. COVID-19: the case for health-care worker screening to prevent hospital transmission. Lancet. 2020;394:1418-20. https://doi.org/10.1016/S0140-6736(20)30917-X. 
29. Escobar DJ, Lanzi M, Saberi P, Love R, Linkin DR, Kelly JJ, et al. Mitigation of a COVID-19 outbreak in a nursing home through serial testing of residents and staff. Clin Infect Dis. 2020. https://doi.org/10.1093/cid/ciaa1021.

30. Goldberg SA, Lennerz J, Klompas M, Mark E, Pierce VM, Thompson RW, et al. Presymptomatic transmission of SARS-CoV-2 amongst residents and staff at a skilled nursing facility: results of real-time PCR and serologic testing. Clin Infect Dis. 2020. https://doi.org/10.1093/cid/ciaa991.

31. Wachholz PA, Jacinto AF. Comment on: Coronavirus disease 2019 in geriatrics and long-term care: the ABCDs of COVID-19. J Am Geriatr Soc. 2020;68:1168-9. https://doi.org/10.1111/jgs.16551.

32. Gilbert M, Pullano G, Pinotti F, Valdano E, Poletto C, Boëlle P-Y, et al. Preparedness and vulnerability of African countries against importations of COVID-19: a modelling study. Lancet. 2020;395:871-7. https://doi.org/10. 1016/S0140-6736(20)30411-6.

33. Narayanan K, Frost I, Heidarzadeh A, Tseng KK, Banerjee S, John J, et al. Pooling RT-PCR or NGS samples has the potential to cost-effectively generate estimates of COVID-19 prevalence in resource limited environments. medRxiv. 2020. https://doi.org/10.1101/2020.04.03. 20051995.

34. Hogan CA, Sahoo MK, Pinsky BA. Sample pooling as a strategy to detect community transmission of SARS-CoV-2. JAMA. 2020. https://doi.org/10. 1001/jama.2020.5445.

35. Mallapaty S. The mathematical strategy that could transform coronavirus testing. Nature. 2020. https://doi.org/10.1038/d41586-020-02053-6.

36. Pouwels KB, Roope LSJ, Barnett A, Hunter DJ, Nolan TM, Clarke PM. Group testing for SARS-CoV-2: forward to the past? PharmacoEconomics Open. 2020;:1-4. https://doi.org/10.1007/s41669-020-00217-8.

37. Eberhardt JN, Breuckmann NP, Eberhardt CS. Multi-stage group testing improves efficiency of large-scale COVID-19 screening. J Clin Virol. 2020;128: 104382. https://doi.org/10.1016/j.jcv.2020.104382.

38. Yelin I, Aharony N, Shaer Tamar E, Argoetti A, Messer E, Berenbaum D, et al. Evaluation of COVID-19 RT-qPCR test in multi-sample pools. Clin Infect Dis. 2020. https://doi.org/10.1093/cid/ciaa531.

39. Duval A, Smith D, Guillemot D, Opatowski L, Temime L. CTCmodeler: an agent-based framework to simulate pathogen transmission along an inter-individual contact network in a hospital. In: Computational science - ICCS 2019: 19th international conference, faro, portugal, june 12-14, 2019, proceedings, part II. Rodrigues JMF, Cardoso PJS, Monteiro J, Lam R, Krzhizhanovskaya W, Lees MH, et al., editors. Cham: Springer International Publishing; 2019. p. 477-487. https://doi.org/10.1007/978-3030-22741-8_34.

40. Grimm V, Berger U, DeAngelis DL, Polhill JG, Giske J, Railsback SF. The ODD protocol: a review and first update. Ecol Model. 2010;221:2760-8. https://doi. org/10.1016/j.ecolmodel.2010.08.019.

41. Duval A, Obadia T, Martinet L, Boëlle P-Y, Fleury E, Guillemot D, et al. Measuring dynamic social contacts in a rehabilitation hospital: effect of wards, patient and staff characteristics. Sci Rep. 2018;8:1686. https://doi.org/ 10.1038/s41598-018-20008-w.

42. Vanhems P, Barrat A, Cattuto C, Pinton J-F, Khanafer N, Régis C, et al. Estimating potential infection transmission routes in hospital wards using wearable proximity sensors. PLoS One. 2013;8:e73970. https://doi.org/10. 1371/journal.pone.0073970.

43. Temime L, Gustin M-P, Duval A, Buetti N, Crépey P, Guillemot D, et al. A conceptual discussion about R0 of SARS-COV-2 in healthcare settings. Clin Infect Dis. 2020. https://doi.org/10.1093/cid/ciaa682.

44. Salje H, Tran Kiem C, Lefrancq N, Courtejoie N, Bosetti P, Paireau J, et al. Estimating the burden of SARS-CoV-2 in France. Science. 2020;369:208-11. https://doi.org/10.1126/science.abc3517.

45. Béraud G, Kazmercziak S, Beutels P, Levy-Bruhl D, Lenne X, Mielcarek N, et al. The French connection: the first large population-based contact survey in France relevant for the spread of infectious diseases. PLoS One. 2015;10: e0133203. https://doi.org/10.1371/journal.pone.0133203.

46. Davies NG, Kucharski AJ, Eggo RM, Gimma A, Edmunds WJ, Centre for the Mathematical Modelling of Infectious Diseases COVID-19 working group. Effects of non-pharmaceutical interventions on COVID-19 cases, deaths, and demand for hospital services in the UK: a modelling study. Lancet Public Health. 2020;5:e375-85. https://doi.org/10.1016/S2468-2667(20)30133-X.

47. Prem K, Liu Y, Russell TW, Kucharski AJ, Eggo RM, Davies N, et al. The effect of control strategies to reduce social mixing on outcomes of the COVID-19 epidemic in Wuhan, China: a modelling study. Lancet Public Health. 2020;5: e261-70. https://doi.org/10.1016/S2468-2667(20)30073-6.
48. Truelove S, Abrahim O, Altare C, Lauer SA, Grantz KH, Azman AS, et al. The potential impact of COVID-19 in refugee camps in Bangladesh and beyond: a modeling study. PLoS Med. 2020;17:e1003144. https://doi.org/10.1371/ journal.pmed.1003144.

49. He X, Lau EHY, Wu P, Deng X, Wang J, Hao X, et al. Temporal dynamics in viral shedding and transmissibility of COVID-19. Nat Med. 2020;26:672-5. https://doi.org/10.1038/s41591-020-0869-5.

50. Wei WE, Li Z, Chiew CJ, Yong SE, Toh MP, Lee VJ. Presymptomatic transmission of SARS-CoV-2 - Singapore, January 23-March 16, 2020. MMWR Morb Mortal Wkly Rep. 2020;69:411-5. https://doi.org/10.15585/mmwr. mm6914e1.

51. Buitrago-Garcia D, Egli-Gany D, Counotte MJ, Hossmann S, Imeri H, Ipekci AM, et al. Occurrence and transmission potential of asymptomatic and presymptomatic SARS-CoV-2 infections: a living systematic review and meta-analysis. PLoS Med. 2020;17:e1003346. https://doi.org/10.1371/journal. pmed.1003346.

52. Wu Z, McGoogan JM. Characteristics of and important lessons from the coronavirus disease 2019 (COVID-19) outbreak in China: summary of a report of 72314 cases from the Chinese Center for Disease Control and Prevention. JAMA. 2020;323:1239-42. https://doi.org/10.1001/jama.2020. 2648.

53. Fouillet A, Bousquet V, Pontais I, Gallay A, Caserio-Schönemann C. The French Emergency Department OSCOUR Network: evaluation after a 10-year existence. Online J Public health Inform. 2015;7. https://doi.org/10.5210/ ojphi.v7i1.5740.

54. Kucirka LM, Lauer SA, Laeyendecker O, Boon D, Lessler J. Variation in falsenegative rate of reverse transcriptase polymerase chain reaction-based SARS-CoV-2 tests by time since exposure. Ann Intern Med. 2020. https://doi. org/10.7326/M20-1495.

55. Duval A. Comprendre et contrôler la transmission des bactéries multirésistantes par l'analyse et la modélisation des réseaux d'interactions interindividuelles en milieu hospitalier. Doctoral dissertation; 2019.

56. de Salazar A, Aguilera A, Trastoy R, Fuentes A, Alados JC, Causse M, et al. Sample pooling for SARS-COV-2 RT-PCR screening. Clin Microbiol Infect. 2020. https://doi.org/10.1016/j.cmi.2020.09.008.

57. Nguyen NT, Aprahamian H, Bish EK, Bish DR. A methodology for deriving the sensitivity of pooled testing, based on viral load progression and pooling dilution. J Transl Med. 2019;17:252. https://doi.org/10.1186/s12967-019-1992-2.

58. Obadia T, Opatowski L, Temime L, Herrmann J-L, Fleury É, Boëlle P-Y, et al. Interindividual contacts and carriage of methicillin-resistant Staphylococcus aureus: a nested case-control study. Infect Control Hosp Epidemiol. 2015;36: 922-9. https://doi.org/10.1017/ice.2015.89.

59. Zhang J, Litvinova M, Wang W, Wang Y, Deng X, Chen X, et al. Evolving epidemiology and transmission dynamics of coronavirus disease 2019 outside Hubei province, China: a descriptive and modelling study. Lancet Infect Dis. 2020;20:793-802. https://doi.org/10.1016/S1473-3099(20)30230-9.

60. Nishiura H, Kobayashi T, Miyama T, Suzuki A, Jung S-M, Hayashi K, et al. Estimation of the asymptomatic ratio of novel coronavirus infections (COVID19). Int J Infect Dis. 2020;94:154-5. https://doi.org/10.1016/j.jijd.2020.03.020.

61. Mizumoto K, Kagaya K, Zarebski A, Chowell G. Estimating the asymptomatic proportion of coronavirus disease 2019 (COVID-19) cases on board the Diamond Princess cruise ship, Yokohama, Japan, 2020. Euro Surveill. 2020;25. https://doi.org/10.2807/1560-7917.ES.2020.25.10.2000180.

62. Lohse S, Pfuhl T, Berkó-Göttel B, Rissland J, Geißler T, Gärtner B, et al. Pooling of samples for testing for SARS-CoV-2 in asymptomatic people. Lancet Infect Dis. 2020. https://doi.org/10.1016/S1473-3099(20)30362-5.

63. World Health Organization. Diagnostic testing for SARS-CoV-2. Interim Report. World Health Organization; 2020.

64. Lee J, Kim SY, Sung H, Lee SW, Lee H, Roh KH, et al. Challenges and issues of SARS-CoV-2 pool testing. Lancet Infect Dis. 2020;20:1232-3. https://doi. org/10.1016/S1473-3099(20)30516-8.

65. Ghosh S, Rajwade A, Krishna S, Gopalkrishnan N, Schaus TE, Chakravarthy A, et al. Tapestry: a single-round smart pooling technique for COVID-19 testing. medRxiv. 2020. https://doi.org/10.1101/2020.04.23.20077727.

66. Täufer M. Rapid, large-scale, and effective detection of COVID-19 via nonadaptive testing. J Theor Biol. 2020;506:110450. https://doi.org/10.1016/j.jtbi. 2020.110450.

67. Dorfman R. The detection of defective members of large populations. Ann Math Statist. 1943;14:436-40. https://doi.org/10.1214/aoms/1177731363.

68. Borges do Nascimento IJ, Cacic N, Abdulazeem HM, von Groote TC, Jayarajah U, Weerasekara I, et al. Novel coronavirus infection (COVID-19) in 
humans: a scoping review and meta-analysis. J Clin Med. 2020;9. https://doi. org/10.3390/jcm9040941.

69. Palmer S, Torgerson DJ. Economic notes: definitions of efficiency. BMJ. 1999; 318:1136. https://doi.org/10.1136/bmi.318.7191.1136.

70. Shiell A, Donaldson C, Mitton C, Currie G. Health economic evaluation. J Epidemiol Community Health. 2002;56:85-8. https://doi.org/10.1136/jech.56. 2.85 .

71. Ben-Ami R, Klochendler A, Seidel M, Sido T, Gurel-Gurevich O, Yassour M, et al. Large-scale implementation of pooled RNA extraction and RT-PCR for SARS-CoV-2 detection. Clin Microbiol Infect. 2020. https://doi.org/10.1016/j. cmi.2020.06.009.

72. Gaur S, Dumyati G, Nace DA, Jump RLP. Unprecedented solutions for extraordinary times: helping long-term care settings deal with the COVID-19 pandemic. Infect Control Hosp Epidemiol. 2020;41:729-30. https://doi.org/ 10.1017/ice.2020.98.

73. Grassly NC, Pons-Salort M, Parker EPK, White PJ, Ferguson NM, Imperia College COVID-19 Response Team. Comparison of molecular testing strategies for COVID-19 control: a mathematical modelling study. Lancet Infect Dis. 2020. https://doi.org/10.1016/S1473-3099(20)30630-7.

74. Kucharski AJ, Klepac P, Conlan AJK, Kissler SM, Tang ML, Fry H, et al. Effectiveness of isolation, testing, contact tracing, and physical distancing on reducing transmission of SARS-CoV-2 in different settings: a mathematical modelling study. Lancet Infect Dis. 2020;20:1151-60. https:// doi.org/10.1016/S1473-3099(20)30457-6.

75. Ferretti L, Wymant C, Kendall M, Zhao L, Nurtay A, Abeler-Dörner L, et al. Quantifying SARS-CoV-2 transmission suggests epidemic control with digital contact tracing. Science. 2020;368. https://doi.org/10.1126/science.abb6936.

76. Zheng Z, Peng F, Xu B, Zhao J, Liu H, Peng J, et al. Risk factors of critical \& mortal COVID-19 cases: a systematic literature review and meta-analysis. J Infect. 2020;81:e16-25. https://doi.org/10.1016/j.jinf.2020.04.021.

77. Ma Y, Hou L, Yang $X$, Huang Z, Yang $X$, Zhao N, et al. The association between frailty and severe disease among COVID-19 patients aged over 60 years in China: a prospective cohort study. BMC Med. 2020;18:274. https:// doi.org/10.1186/s12916-020-01761-0.

78. Petrilli CM, Jones SA, Yang J, Rajagopalan H, O'Donnell L, Chernyak Y, et al. Factors associated with hospital admission and critical illness among 5279 people with coronavirus disease 2019 in New York City: prospective cohort study. BMJ. 2020;369:m1966. https://doi.org/10.1136/bmj.m1966.

79. Ladhani SN, Chow JY, Janarthanan R, Fok J, Crawley-Boevey E, Vusirikala A, et al. Investigation of SARS-CoV-2 outbreaks in six care homes in London, April 2020. EClinicalMedicine. 2020;100533. https://doi.org/10.1016/j.eclinm. 2020.100533.

80. van Doremalen N, Bushmaker T, Morris DH, Holbrook MG, Gamble A, Williamson BN, et al. Aerosol and surface stability of SARS-CoV-2 as compared with SARS-CoV-1. N Engl J Med. 2020;382:1564-7. https://doi.org/ 10.1056/NEJMc2004973.

81. Nelson A, Kassimatis J, Estoque J, Yang C, McKee G, Bryce E, et al. Environmental detection of severe acute respiratory syndrome coronavirus 2 (SARS-CoV-2) from medical equipment in long-term care facilities undergoing COVID-19 outbreaks. Am J Infect Control. 2020. https://doi.org/ 10.1016/j.jajic.2020.07.001

82. Mondelli MU, Colaneri M, Seminari EM, Baldanti F, Bruno R. Low risk of SARS-CoV-2 transmission by fomites in real-life conditions. Lancet Infect Dis. 2020. https://doi.org/10.1016/S1473-3099(20)30678-2.

83. Assab R, Temime $L$. The role of hand hygiene in controlling norovirus spread in nursing homes. BMC Infect Dis. 2016;16:395. https://doi.org/10. 1186/s12879-016-1702-0.

\section{Publisher's Note}

Springer Nature remains neutral with regard to jurisdictional claims in published maps and institutional affiliations.

Ready to submit your research? Choose BMC and benefit from:

- fast, convenient online submission

- thorough peer review by experienced researchers in your field

- rapid publication on acceptance

- support for research data, including large and complex data types

- gold Open Access which fosters wider collaboration and increased citations

- maximum visibility for your research: over $100 \mathrm{M}$ website views per year

At BMC, research is always in progress.

Learn more biomedcentral.com/submissions 